\title{
O ENSINO DE TEATRO NO IFMA-CAMPUS AÇAILÂNDIA: \\ UM DISCURSO CONTEMPORÂNEO
}

\author{
Felipe Feitosa Silva ${ }^{1}$ \\ Mayara Karla da Anunciação Silva² \\ Rafaela Soares Mendonça ${ }^{3}$
}

\section{INTRODUÇÃO}

Há algum tempo a perspectiva dos Institutos Federais de Educação estava voltada para a formação profissional para o mercado de trabalho. Desta forma, as matrizes curriculares voltavam-se para o fortalecimento das disciplinas técnicas em detrimento das disciplinas do núcleo comum. Diante disso, surge a seguinte inquietação: em que âmbito situa-se a educação cultural e artística nesse contexto profissional em que o Instituto Federal está inserido e como desenvolvêla?.

Compreende-se que o processo de ensino-aprendizagem em Teatro permite ao educando expressar-se de forma crítica e vivenciar culturalmente de forma ativa e expressiva sua presença no mundo e sobre o mundo. Desta forma, com este estudo, busca-se resgatar a história do ensino de Teatro no IFMA, Campus Açailândia-MA, a fim de analisar de forma científica as experiências historicizadas em Teatro, com intuito de produzir registros sobre as práticas realizadas dentro e fora da escola.

Assim, busca-se compreender a importância da experiência estética teatral para o processo de ensino e aprendizagem, destacando-se as experiências do ensino de Teatro e como estas têm contribuído para uma mudança cultural no IFMA de Açailândia-MA, relacionados aos processos de diálogo entre o criador, a obra e o espectador.

\section{O ENSINO DE ARTE}

\footnotetext{
${ }^{1}$ Aluno do Curso de Automação Industrial, IFMA. E-mail: felipe.feitosa0607@gmail.com 2Mestre em Cultura e Sociedade, UFMA. E-mail: mayarakarla@ifma.edu.br 3Bibliotecária-Documentalista, IFMA. E-mail: rafaela.soares@ifma.edu.br
} 
O ensino de Arte no Brasil é uma conquista a várias reivindicações sociais e filosóficas, expressadas nas falas e ações dos arte-educadores brasileiros. Nesse cenário a categoria de Teatro-Educação é algo recente, que permeia as discussões educacionais desde o ano de 1948, com a criação da Escolinha de Arte em Pernambuco.

O ensino de Arte no Brasil ganha status de disciplina a partir da LDBN no $5.692 / 71$, enquanto que sua relação com o conhecimento em Teatro demorou um pouco. O cenário diagnosticava um ensino tradicional e arcaico, sem abertura para propostas inovadoras ou para outras linguagens artísticas que não fosse o desenho técnico e industrial (BRANDÃO, 2007).

O currículo cênico na escola devia transpor uma pedagogia estética ou meramente instrumental, em que as encenações cênicas eram utilizadas apenas como ferramenta metodológica para auxiliar o ensino e aprendizagem de disciplinas "ditas superiores" no currículo escolar.

Destarte, apostava-se na perspectiva de estabelecer as linguagens artísticas no âmbito acadêmico, possibilitando a formação de profissionais em Artes Visuais, Teatro, Música e Dança, ampliando a possibilidade do ensino de Arte, num viés crítico e cultural. A dificuldade, porém, encontrava-se em ultrapassar as barreiras de um ensino espontaneísta para um ensino científico e de fato artístico e cultural.

Com formatos claros e definidos, a arte-educação chega aos anos 90 com características e funções próprias na área educacional, ocorrendo, no ano de 1996, a criação da Lei de Diretrizes e Bases da Educação Brasileira (LDBN), № 9.394/96, que trouxe um capítulo específico, tratando somente da educação profissional com uma visão desprovida de assistencialismo e preconceitos sociais anteriormente estereotipados. Desta forma, toma-se como fundamento a LDBN no 9.394/96, Art.1으, $\S 2^{\circ}$ estabelece que: "A educação escolar deverá vincular-se ao mundo do trabalho e à prática social." (BRASIL, 1996, p. 1).

A mesma LDBN também trouxe suas mudanças para o ensino de Arte, a partir do momento que reconhece a importância da educação em arte para a formação do indivíduo na Educação Básica ou na Educação Profissional e Tecnológica, desmistificando a visão de educandos e educadores de arte como um 
artigo de luxo, um instrumento de lazer ou um mecanismo para treinamento e formação de mão-de-obra. Descaracterizando também, o conceito de que:

O verdadeiro ensino da arte foi reservado às horas de ócio das classes superiores, dando-se apenas nos "conservatórios" e "academias" particulares. Na escola oficial a arte sempre entrou pela porta dos fundos e, ainda assim, de maneira disfarçada. (DUARTE JÚNIOR, 1988, p. 77).

Desta forma, a disciplina de Arte tem seu reconhecimento enquanto campo epistemológico, abrindo possibilidades também no campo acadêmico com cursos de graduação e pós-graduação na área de Arte.

Do mesmo modo, os Parâmetros curriculares Nacionais (PCN's) foram elaborados no ano de 1997 por estudiosos espanhóis para nortear o ensino do currículo escolar. É certo que os PCN's enfatizam que os educadores devem conhecer as várias linguagens que visam à formação artística e estética dos alunos, referindo-se às linguagens artísticas, como Artes Visuais, a Música, o Teatro e a Dança. E as escolas técnicas, por sua vez, podem oferecer um ambiente propício para o desenvolvimento deste ensino, a fim de que o aluno se aproprie de conhecimento, uma vez que almeja-se uma Educação Básica de qualidade. (BRASIL, 1997).

O surgimento dessas diretrizes educacionais favoreceram a propagação do ensino das artes, possibilitando aos indivíduos o aprendizado, análise e diálogo com os diferentes contextos, desenvolvendo uma prática educativa cultural.

Sendo assim, no cenário atual do ensino de arte, é importante que o educando saiba o sentido artístico em suas experiências, para que o ensino de arte não se torne vazio, sem objetivos. O educando deve ter consciência que o dançar, o dramatizar e o cantar são experiências estéticas sensíveis, ações artísticas que não se tratam apenas de um lazer, de um espontaneísmo, mas que referendam toda a trajetória de um diálogo entre si mesmo e sua cultura, enriquecendo seu saber e sua leitura acerca do mundo.

\section{O ENSINO DE TEATRO NO IFMA - CAMPUS AÇAILÂNDIA}

O ensino em teatro deve ser concebido como estratégia de relacionar o ensino de arte às práticas sociais, a fim de que essas práticas sejam significativas e 
que adentrem ao cotidiano do aluno, relacionando-se com o contexto em que o educando está inserido. Nessa perspectiva, reforça-se que:

Refletir sobre o cotidiano das aulas de teatro é, assim, um trabalho que busca compreender as táticas utilizadas pelos professores e pelos alunos em seu fazer didático-pedagógico, penetrando astuciosamente e de modo particular em cada momento. (TELLES, 2013, p. 17).

É preciso registrar como os processos educacionais se desenvolvem na disciplina de Arte, mais especificamente as ações que norteiam o ensino de Teatro. Os registros são a memória viva das construções nesse espaço educacional que auxiliam no desdobramento de novas metodologias e soluções possíveis para este ensino ou até mesmo para a ausência dele.

As práticas e experiências construídas no âmbito escolar apontam as dificuldades, superação e inovações no ensino de Teatro. Articula-se nesse processo a história, experiências e saberes construídos pelas vivências professorais, estimuladas pelas circunstâncias desfavoráveis a esse ensino.

Nesta perspectiva é que o ensino de teatro possibilita ao educando a construção de um conhecimento de forma lúdica e concreta, além de desenvolver sua criatividade e educação corporal tão enfatizada pelos Parâmetros Curriculares Nacionais - PCNEM de Arte e pela obrigatoriedade do ensino de Arte na escola, independente da sua linguagem (BRASIL, 2000).

O teatro enquanto ação dramática possui uma linguagem social e cultural que consegue disseminar e compartilhar essa linguagem com 0 universo comunitário à sua volta, neste caso em específico a cidade Açailândia no Maranhão.

O ensino de Teatro no IFMA, Campus Açailândia, tem possibilitado o desenvolvimento artístico e estético no aluno, para que ele possa ter experiências sensíveis, estimulando sua percepção e imaginação tanto ao realizar formas artísticas quanto no ato de apreciar as formas de uma obra, pela natureza e nas diversas culturas, o que se torna difícil se o aluno não conhecer a sua própria cultura e entender os símbolos que a constituem.

As performances produzidas pelos alunos são provenientes de estudos e pesquisas realizadas em torno de uma temática seja ela cultural, ambiental, social, científica. A intenção é permitir que após estudar e pesquisar, estenda-se o 
conhecimento adquirido por meio de linguagens artísticas que transmitam valores estéticos.

Desta forma, torna-se necessário destacar o impacto desse processo educacional como mola propulsora no desenvolvimento de uma ação cultural que possibilite aos sujeitos "um processo continuado de exercício de sua autonomia crítica e criativa - assumindo-se enquanto sujeito da própria história, tornando-se capaz de (re)desenhar um projeto para seu futuro". (DESGRANGES, 2011, p.24).

Atualmente, o campo da arte-educação possui sua gama de importância, pois, suscita uma reflexão sobre a realidade e o campo de atuação profissional de forma humanística, em que a sala de aula é local de debate e discussões e, os processos metodológicos são pautados nas tendências pedagógicas desenvolvidas e constituídas ao longo dos tempos.

\section{METODOLOGIA}

O desenvolvimento da pesquisa consiste na análise e investigação histórica e metodológica do ensino do Teatro-educação no IFMA de Açailândia-MA no período de 2011 a 2015.

Inicialmente foram realizadas pesquisas bibliográficas e documentais sobre a temática estudada, a fim de associar a teoria com o conhecimento empírico.

Para análise desse contexto, a pesquisa desenvolve-se por meio do estudo do campo teórico sobre os fundamentos que norteiam a prática reflexiva, educativa e a concepção de educação em Teatro, possibilitando um olhar aguçado nas construções das proposições que norteiam o processo de pesquisa. Desta forma, o presente trabalho assume a característica de pesquisa de natureza observacional, do tipo descritiva, com abordagem qualitativa.

Durante o processo de observação foram coletados dados que, posteriormente foram catalogados, a exemplo, têm-se as apresentações realizadas pelos alunos e suas relações com o conteúdo ministrado em sala de aula, percebendo de que forma os discentes conseguiam desenvolver criativamente a construção das peças e performances teatrais.

Cada apresentação foi catalogada de acordo com o período apresentado e o objetivo didático. Os discentes que faziam parte do elenco foram entrevistados de modo informal, a fim de que fossem constatadas as suas impressões sobre a 
aquisição do conhecimento mediante a experiência estética do ato de encenar. Assim como os alunos protagonistas, também foram entrevistados informalmente, os espectadores que assistiram às performances para identificar-se de que forma ocorria a recepção da obra mediante a construção do conhecimento cênico e cultural.

Após essas etapas foram construídos momentos de reflexão com os grupos de discentes para avaliar a mudança cultural referente à construção do conhecimento cênico e das suas concepções sobre a realidade vivenciada.

Segundo Xavier (2010) interpretação e redação da pesquisa merecem a devida atenção, pois, as interpretações dos dados obtidos por meio da pesquisa deverão estar pautadas na observação e no instrumento de coleta de dados. Com efeito, busca-se no tópico a seguir, realizar a abordagem sobre os resultados e discussões, a fim de dimensionar a observação científica realizada pelos pesquisadores no processo investigativo.

\section{RESULTADOS E DISCUSSÃO}

No início do desenvolvimento da linguagem cênica no IFMA - Campus Açailândia, observou-se o predomínio de uma cultura capitalista voltada para uma educação que objetivava apenas o mercado de trabalho.

As descobertas científicas realizadas auxiliaram no processo de desmistificação da arte como lazer ou para ocupação do ócio, favorecendo a valorização e mudança de concepções em meio à sociedade. Apesar da melhoria da elevação das concepções em relação à arte, a educação em arte ainda sofre com processos de estranhamento e desvalorização dos seus variados conteúdos.

O teatro, especificamente, na educação escolar tem obtido seus avanços, fruto das práticas contemporâneas, do fazer artístico, autobiografias da práxis de professores de arte e, principalmente, da realidade da sala de aula, local formal em que são ministrados os conteúdos de artísticos.

Como parte dessas modificações, pautou-se na aprovação do projeto de Lei de $n^{0} 7.032 / 10$ que torna obrigatório o ensino de artes visuais, teatro, dança e música, sendo uma conquista no ensino das linguagens artísticas como componente curricular, fundamentando-se também na LDBN no 9.394/96 no Art.26 $§ 2^{\circ}$ onde afirma-se que: "O ensino de Artes constituíra componente curricular obrigatório, nos 
diversos níveis da educação básica de forma a promover o desenvolvimento cultural do aluno". (BRANDÃO, 2007, p. 41).

Essas mudanças influenciaram diretamente na metodologia do ensino de teatro no IFMA - Campus Açailândia, que em um mundo contemporâneo adota a compreensão da narrativa histórica do homem e construída pelo homem nos mais variados contextos.

A ação cultural através do diálogo entre criador, obra e espectador permitiram significar e (re)significar o que os discentes viam, o que sentiam, o que percebiam, possibilitando diálogos consigo mesmos e com os outros, já que o teatro é área de conhecimento que:

\begin{abstract}
É uma ação profunda porque cultural, não apenas aparente, de modo individualizado e descontextualizado da realidade, do meio, da vida. Nesse sentido, [...] ninguém conscientizará ninguém. $O$ educador e o povo se conscientizam através do movimento dialético entre a reflexão crítica sobre a ação anterior e a subsequente ação no processo [...]. (FREIRE, 1982, p. 109).
\end{abstract}

Assim constatou-se, que as apresentações criadas pelos discentes possuíam uma gama de conhecimentos interdisciplinares que abordavam conteúdos além das disciplinas do currículo escolar formal. As encenações e performances eram repletas de conhecimentos do currículo oculto, fruto da hibridização vivenciada pelos discentes na realidade contemporânea.

Os discentes eram protagonistas na criação e na construção de um conhecimento inovador e audacioso, construindo uma linguagem própria de sentidos, favorecendo a descoberta e construção de novos saberes, pois, "podemos conceber, assim, que a tomada de consciência se efetiva como leitura de mundo. Apropriar-se da linguagem é ganhar condições para essa leitura". (DESGRANGES, 2011, p. 23).

A partir do ensino de teatro no IFMA - Campus Açailândia, foi perceptível a mudança de ponto de vista relacionado ao fazer artístico-cultural. Quanto aos discentes, foi possível estabelecer a construção de uma linguagem própria de sentidos, possibilitando a estes, a descoberta e construção de novos saberes, adquirindo assim, a aquisição da linguagem cênica.

Em relação ao espectador, foi possível identificar no início da observação a dificuldade de dialogar com a obra, de construir e reconhecer a ação teatral, para 
posterior mudança cultural. Aos poucos, com a aquisição da linguagem cênica, os discentes-espectadores conseguiam contextualizar a linguagem teatral com 0 discurso da cena contemporânea, o que evidenciava a ação educativa no ensino de teatro.

O ensino de teatro, bem como, as apresentações e performances foram fundamentais para redefinição do Currículo Escolar do IFMA - Campus Açailândia, estes que iam além dos conteúdos das disciplinas do currículo escolar formal, uma vez que as encenações e performances eram repletas de conhecimentos do currículo oculto. Quanto à receptividade pela Sociedade Açailandense, as descobertas científicas auxiliaram no processo de desmistificação da arte como lazer ou para ocupação do ócio.

\section{CONCLUSÃO}

As intervenções realizadas contribuíram para o fortalecimento de um discurso contemporâneo para o ensino de teatro, de forma realista e progressista, aproximando os estudantes do seu legado cultural e artístico da humanidade, permitindo que tenham conhecimento de seus próprios aspectos culturais significativos e de suas diversas manifestações ao longo dos tempos.

O ensino de teatro mobilizou os discentes para um saber teatral que ultrapassou os modelos sistematizados, como o da pedagogia tradicional, renovada e tecnicista; foi necessário compreender o ensino de teatro como um fato cultural, situando cultura como um campo amplo de significados, que gerou uma comunidade de sentidos e pertencimentos, revelando um saber complexo e crítico.

Nessa perspectiva, revelaram-se para a comunidade, ações socioculturais e artísticas que envolvem os sujeitos do ambiente escolar, desenvolvendo nestes uma educação crítica e autônoma.

Contribui-se, assim, para um ensino de arte e de teatro crítico e transformador, pois a partir do momento que o educando produz trabalhos artísticos e conhece essa produção em outras culturas, ele compreende a diversidade de valores que orientam seus modos de pensar e agir, como os da sociedade, sendo capaz de interagir com o mundo e transformá-lo, instigado pelo movimento que gera a ação cultural. 


\section{REFERÊNCIAS}

BRANDÃO, Carlos da Fonseca. LDB passo a passo: Lei de Diretrizes e Bases da Educação Nacional (Lei no 9.394/96), comentada e interpretada, artigo por artigo. 3.ed. Atual. São Paulo: Editora Avercamp, 2007.

BRASIL. Lei n. 9.394, de 20 de dezembro de 1996. Estabelece as diretrizes e bases da educação nacional. Diário Oficial da União, Brasília, DF: 1996. Disponível em:<http://www.planalto.gov.br/ccivil_03/Leis/L9394.htm>. Acesso em: 13 maio. 2016.

- Ministério da Educação. Parâmetros Curriculares Nacionais (Ensino Médio). Brasília, DF: Gráfica do Governo Federal, 2000.

Ministério da Educação. Parâmetros Curriculares Nacionais (Introdução). Brasília, DF: Gráfica do Governo Federal, 1997.

DESGRANGES, Flávio. A pedagogia do teatro: provocação e dialogismo. 3. ed. São Paulo: Editora Hucitec: Edições Mandacaru, 2011.

DUARTE JÚNIOR, João Francisco. Por que arte-educação?. Campinas, Papirus, 1988.

FREIRE, Paulo. Pedagogia do oprimido. Rio de Janeiro: Paz e Terra, 1982.

TELLES, Narciso (Org.). Pedagogia do teatro: práticas contemporâneas na sala de aula. Campinas, SP: Papirus, 2013.

XAVIER, Antonio Carlos. Como fazer e apresentar trabalhos científicos em eventos acadêmicos: [ciências humanas e sociais aplicadas: artigo, resumo, resenha, monografia, tese, dissertação, tcc, projeto, slide]. Recife: Editora Rêspel, 2010. 